Supporting Information

\title{
Manipulating Migration Behavior of Magnetic Graphene Oxide via Magnetic Field Induced Casting and Phase Separation toward High-Performance Hybrid Ultrafiltration Membranes
}

Zhiwei Xu, ${ }^{*}$ Tengfei Wu, Jie Shi, Wei Wang, Kunyue Teng, Xiaoming Qian," Minging Shan, Hui Deng, Xu Tian, Cuiyu Li, Fengyan Li

State Key Laboratory of Separation Membranes and Membrane Processes, School of Textiles, Tianjin Polytechnic University, Tianjin 300387, China

\section{Corresponding Authors}

"E-mail: Zhiwei Xu, xuzhiwei@tjpu.edu.cn Tel/Fax: +86 02283955231

*E-mail: Xiaoming Qian, qianxiaoming@ @ tjpu.edu.cn Tel/Fax: +86 02283955051 


\section{Experimental Section:}

The thermo gravimetric analysis (TGA) curves of $\mathrm{GO}$ and $\mathrm{Fe}_{3} \mathrm{O}_{4} / \mathrm{GO}$ were obtained from a STA409PC.The samples were heated from $25{ }^{\circ} \mathrm{C}$ to $800{ }^{\circ} \mathrm{C}$ at a rate of $10^{\circ} \mathrm{C} / \mathrm{min}$ in an aluminum crucible under $50 \mathrm{~mL} / \mathrm{min}$ of nitrogen purging.

Zeta potential was performed using a Delsa Nano instrument and all data were measured over five times. The samples were dispersed by ultrasonic agitation in DMAc solution at $298.15 \mathrm{~K}$ for $1 \mathrm{~h}$ before tests.

The pore distribution of membranes was measured by bubble point method using a capillary flow porometer (PMI, Ithaca, NY, USA). Wet-up/dry-down mode was used for the test of membranes. Before running the experiments, the membranes were fully wetted with commercial low surface tension liquid Porefil (surface tension of 16 dyn $\left.\mathrm{cm}^{-1}\right)$.

Pure water flux of membranes with an effective area of $19.3 \mathrm{~cm}^{2}$ was conducted on a dead-end membrane system. Both the pure water flux and rejection tests were directed at $25{ }^{\circ} \mathrm{C}$ with a feed pressure of $0.1 \mathrm{MPa}$. Prior to water flux testing, the membranes were pressurized at $0.15 \mathrm{MPa}$ for $1 \mathrm{~h}$ to eliminate the effect of membrane compaction and to obtain stable water flux. Then the water flux, $J\left(\mathrm{~L} \cdot \mathrm{m}^{-2} \cdot \mathrm{h}^{-1}\right)$, was measured at $0.1 \mathrm{MPa}$ and calculated by Eq. (1).

$$
J=\frac{Q}{A \times T}
$$

where $Q(\mathrm{~L})$ is the total volume penetrating through the membrane during the operation time $T(\mathrm{~h})$ with an effective filtration area of $A\left(\mathrm{~m}^{2}\right)$.

The rejection was investigated with $1.0 \mathrm{~g} \mathrm{~L}^{-1} \mathrm{BSA}$ solution using $0.1 \mathrm{M}$ phosphate buffered at $\mathrm{pH}$ 7.4. By monitoring the concentrations of BSA in permeation and feed solutions using a UV spectrophotometer at $280 \mathrm{~nm}$, the BSA rejection, $R(\%)$, was estimated by Eq. (2).

$$
R(\%)=\left(1-\frac{C_{P}}{C_{F}}\right) \times 100
$$

where $C_{P}$ and $C_{F}$ represent the concentrations of BSA in permeation and feed solution, respectively. 
The interaction forces between membrane surface and foulants were quantified by an AFM method, in which BSA, served as a model foulant, were immobilized on the cantilever based on the procedure described in our previous publication. ${ }^{7}$ Briefly, a $\mathrm{Si}_{3} \mathrm{~N}_{4}$ cantilever was modified with amino by activating with oxygen plasma $(150 \mathrm{~W}$, $60 \mathrm{~s}$ ) treatment following by chemical modification with 3-triethoxysilylpropylamine solution $(10 \mathrm{mM})$ for $2 \mathrm{~h}$ at room temperature. Then glutaraldehyde $\left(50 \%\right.$ in $\left.\mathrm{H}_{2} \mathrm{O}\right)$ was utilized to crosslink the AFM tip with BSA for $30 \mathrm{~min}$. The BSA-immobilized probes was washed with phosphate buffer solution (PBS, $\mathrm{pH}=7.4$ ) and subsequently stored in PBS before the force curve measurement. When the membrane surface approached the BSA-immobilized tip, the cantilever would deflect, inducing to a change in photodiode signals. Then the interaction force between the BSA-immobilized AFM tip and membrane surface could be calculated by multiplying the spring constant of the cantilever. The same manner was also applied to the measurement of the forces when the surface was retracted. The AFM was operated in contact mode, with an approach/retraction speed of $0.1 \mu \mathrm{m} \mathrm{s}^{-1}$ and a spring constant of $0.2 \mathrm{Nm}^{-1}$. To minimize the experimental error and to determine the force distribution, approximately 50 approach/retract cycles were conducted on the membrane surface for at least five locations, with 20 measurements at each location.

The membrane strength was measured by testing the tensile strength and elongation-at-break of membrane coupons $(200 \mathrm{~mm} \times 150 \mathrm{~mm} \times 0.2 \mathrm{~mm})$ with a YG028 tensile tester (Wenzhou fangyuan instrument Co. Ltd., China). All the tensile tests were carried out at a stepper motor speed of $10 \mathrm{~mm} / \mathrm{min}$ at room temperature, and the thickness of the sample was measured according to the vernier caliper. Results were averaged from five samples. 


\section{The details for the characters of $\mathrm{Fe}_{3} \mathrm{O}_{4} / \mathrm{GO}$ nanocomposites}

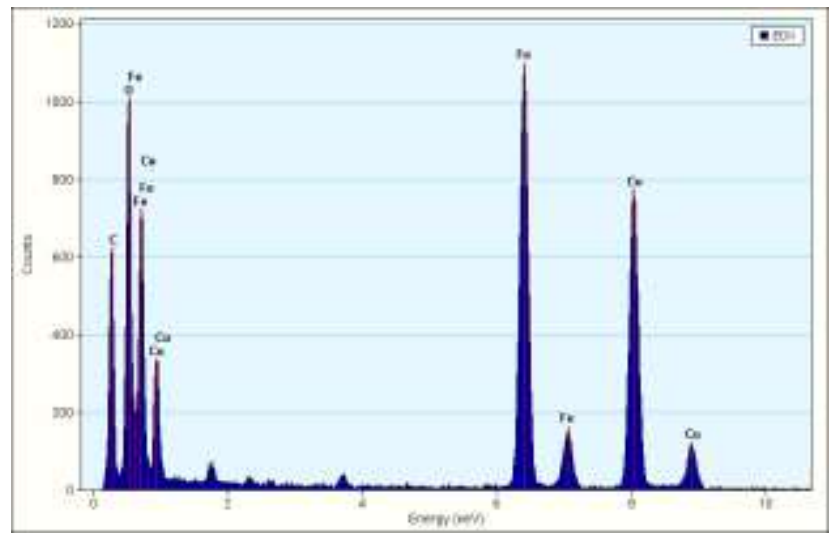

Figure.S1. TEM-EDS spectra of the $\mathrm{Fe}_{3} \mathrm{O}_{4} / \mathrm{GO}$ nanocomposites.
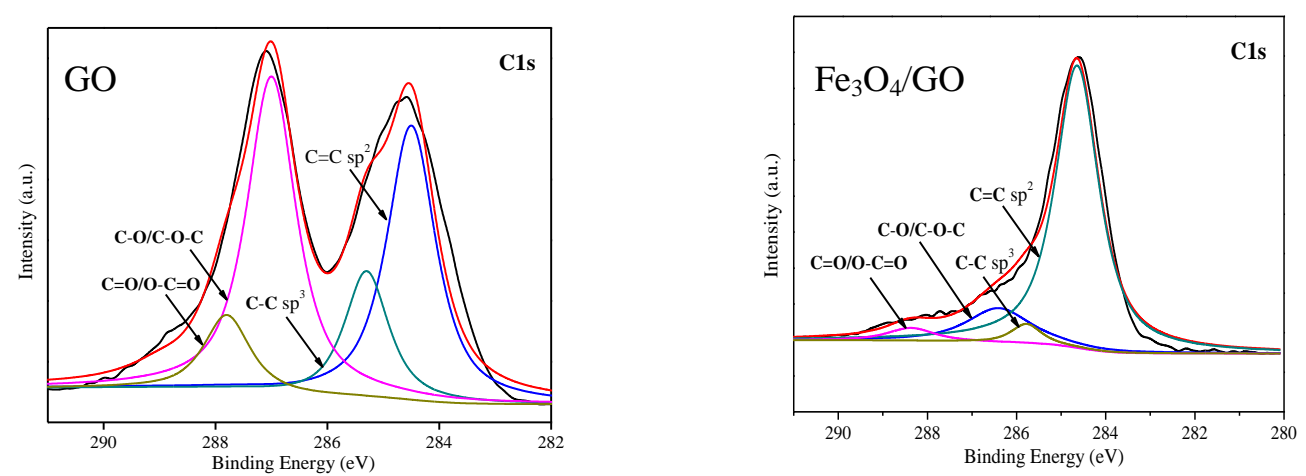

Figure.S2. C 1s spectra of $\mathrm{GO}$ and $\mathrm{Fe}_{3} \mathrm{O}_{4} / \mathrm{GO}$ nanocomposites.

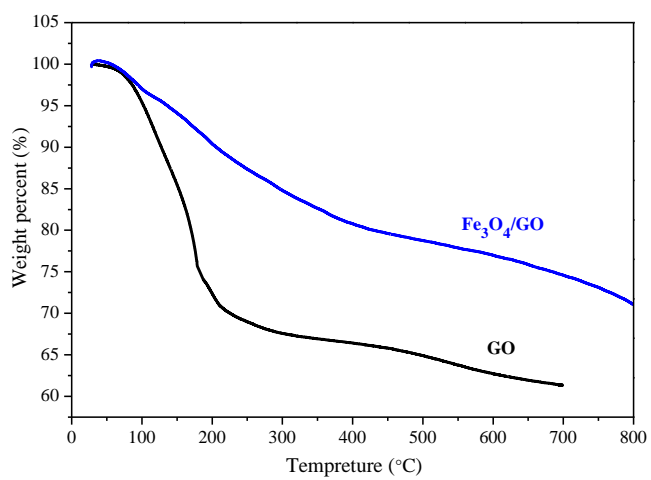

Figure.S3. TGA curves of $\mathrm{GO}$ and $\mathrm{Fe}_{3} \mathrm{O}_{4} / \mathrm{GO}$ nanocomposites. The weight loss stage of GO was range of $70 \sim 230{ }^{\circ} \mathrm{C}$. The weight loss found for GO at the temperature range from 70 to $130{ }^{\circ} \mathrm{C}$ was due to the evaporation of physically absorbed water and the weight loss at range from 130 to $230{ }^{\circ} \mathrm{C}$ was attributed to pyrolysis of the 
oxygen-containing functional groups, yielding $\mathrm{CO}, \mathrm{CO}_{2}$ and water vapor. ${ }^{1}$ For $\mathrm{Fe}_{3} \mathrm{O}_{4} / \mathrm{GO}$ nanocomposites, a slow weight loss at low temperature $\left(<120{ }^{\circ} \mathrm{C}\right)$ was observed, which could be assigned to the loss of the residual or absorbed solvent. Then the slight weight loss occurs from 120 to $380{ }^{\circ} \mathrm{C}$, which might be assigned to the decomposition and vaporization of various oxygen-containing functional groups., 3 Another weight loss in the range $380 \sim 800{ }^{\circ} \mathrm{C}$ might be attributed to the breakdown of the COO- group coordinated with $\mathrm{Fe}_{3} \mathrm{O}_{4}$ nanoparticles in the $\mathrm{Fe}_{3} \mathrm{O}_{4} / \mathrm{GO}$ nanocomposites. ${ }^{4,5}$

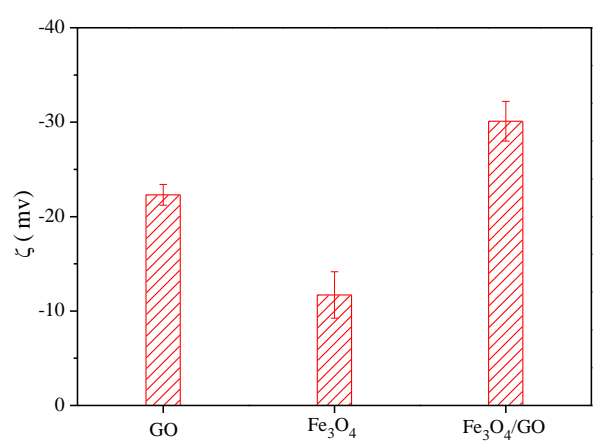

Figure.S4. Zeta potential of $\mathrm{GO}, \mathrm{Fe}_{3} \mathrm{O}_{4}$ and $\mathrm{Fe}_{3} \mathrm{O}_{4} / \mathrm{GO}$ dispersion in DMAc. Zeta potential confers the degree of repulsion between charged particles in dispersion. Therefore, a high zeta potential is an indicator that the dispersion resists agglomeration. ${ }^{6,7}$ As shown in Figure.S4, the zeta potential of $\mathrm{Fe}_{3} \mathrm{O}_{4} / \mathrm{GO}$ in DMAc becomes more negative $(30.1 \mathrm{mV})$ than that of $\mathrm{GO}(22.3 \mathrm{mV})$ and $\mathrm{Fe}_{3} \mathrm{O}_{4}(11.7 \mathrm{mV})$, which suggests the well dispersion of $\mathrm{Fe}_{3} \mathrm{O}_{4} / \mathrm{GO}$ in matrix solution and will be beneficial for the compatibility between $\mathrm{Fe}_{3} \mathrm{O}_{4} / \mathrm{GO}$ nanocomposites and ploymer matrix. 


\section{The details for migration behavior of $\mathrm{Fe}_{3} \mathrm{O}_{4} / \mathrm{GO}$ in membranes}

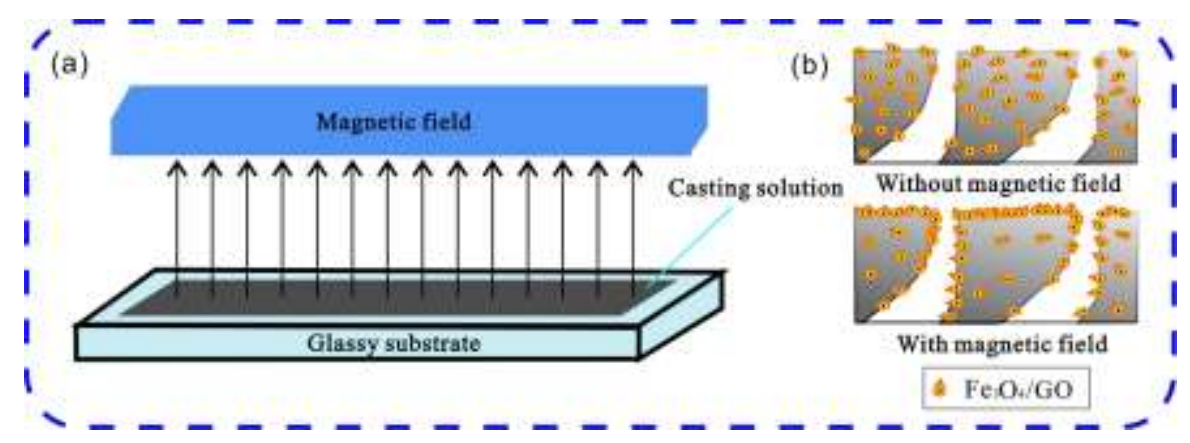

Figure.S5. Scheme of (a) casting under magnetic field and (b) migration of $\mathrm{Fe}_{3} \mathrm{O}_{4} / \mathrm{GO}$ nanocomposites toward membrane and pore surfaces. 

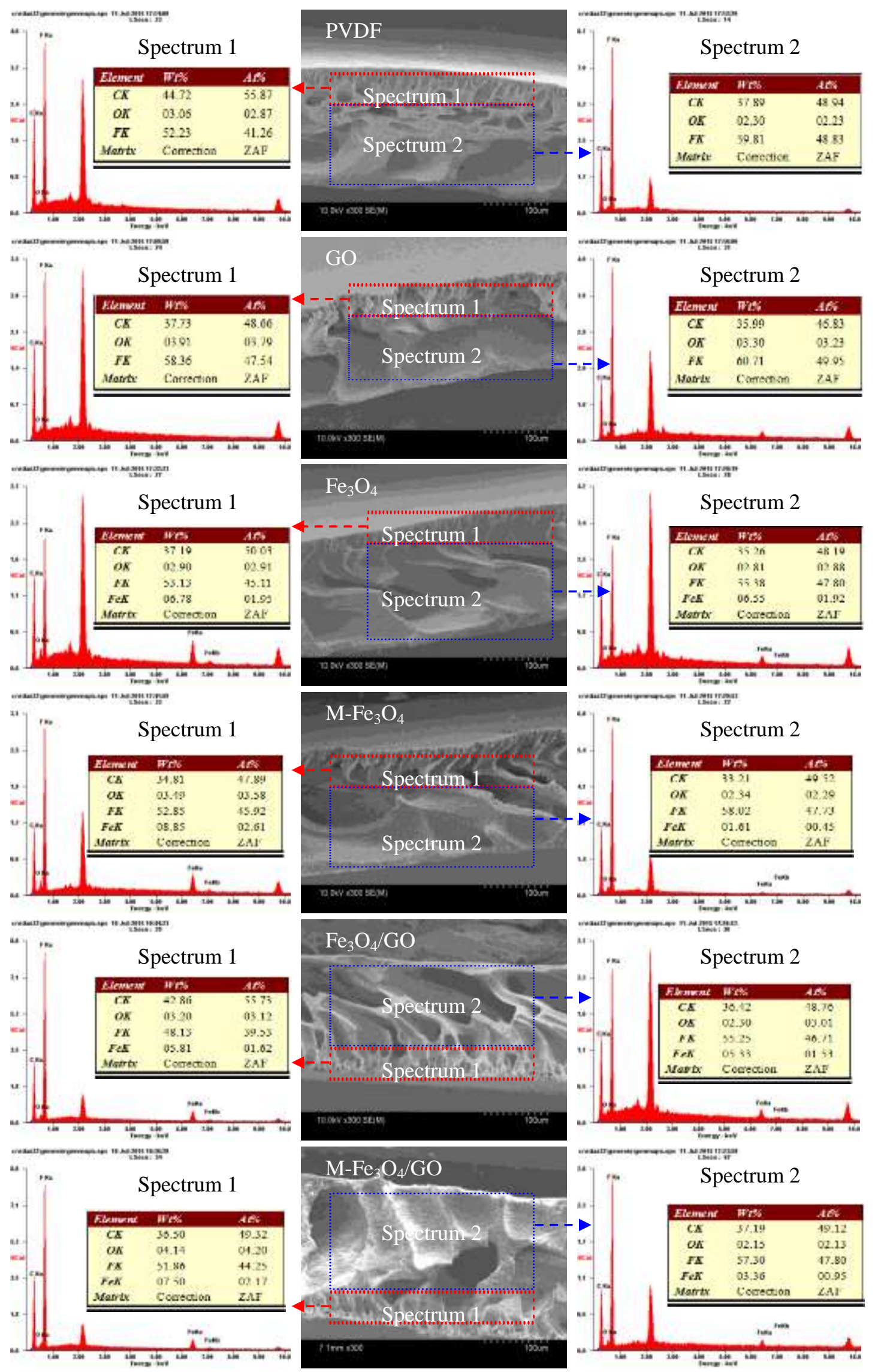

Figure.S6. SEM-EDS analysis of cross-sectional of various membranes. 


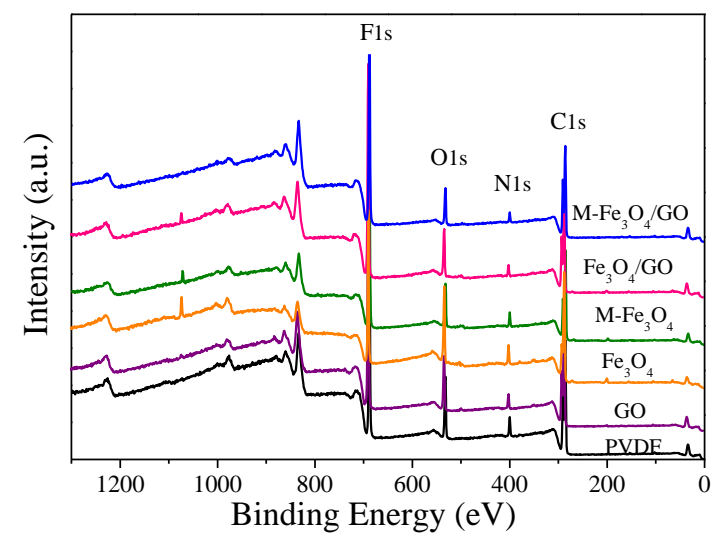

Figure.S7. Wide-scan XPS spectra of various membranes with a take-off angle of $45^{\circ}$.
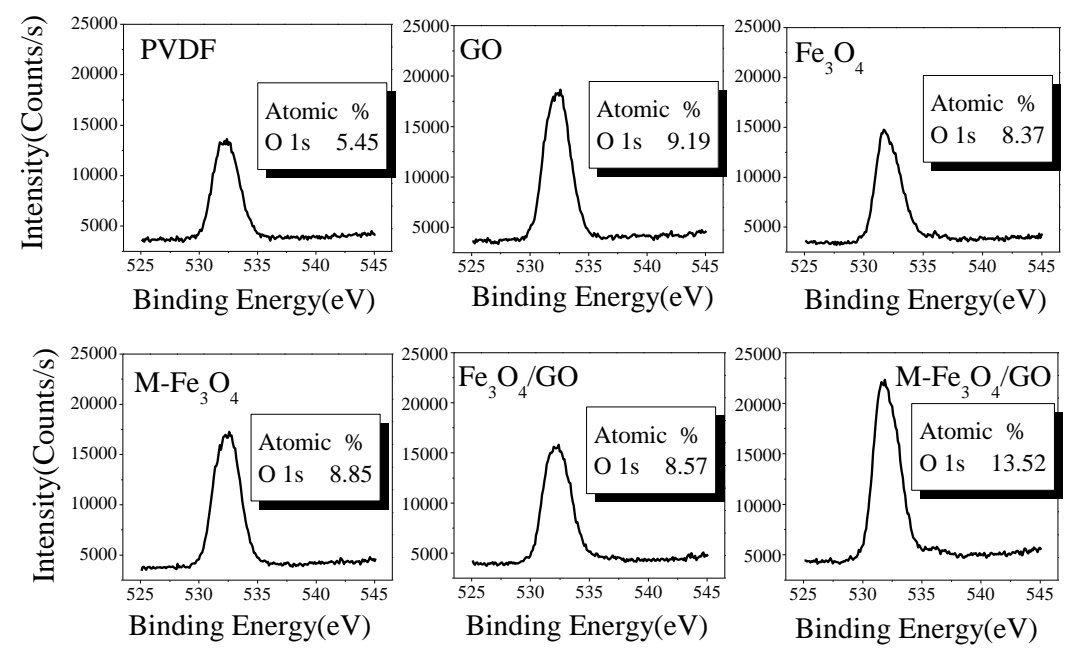

Figure.S8. The XPS O1s scans of various membranes.

Table S1. Elemental composition of various membranes obtained from XPS and EA.

\begin{tabular}{|c|c|c|c|c|c|c|c|c|c|}
\hline \multirow{2}{*}{ Membrane } & \multicolumn{7}{|c|}{$\mathrm{XPS}^{\mathrm{a}}($ At. $\%)$} & \multirow{2}{*}{$\frac{\text { EA (At.\%) }}{O}$} & \multirow{2}{*}{ Osur/Omat $^{\mathrm{b}}$} \\
\hline & $\mathrm{C}$ & $\mathrm{F}$ & $\mathrm{Fe}$ & $\mathrm{O}$ & $\mathrm{N}$ & $\mathrm{O} / \mathrm{N}$ & $\mathrm{O} / \mathrm{F}$ & & \\
\hline PVDF & 37.97 & 51.73 & - & 5.45 & 4.76 & 1.14 & 0.105 & 18.403 & 0.296 \\
\hline GO & 37.36 & 50.64 & - & 9.19 & 2.8 & 3.28 & 0.246 & 20.026 & 0.459 \\
\hline $\mathrm{Fe}_{3} \mathrm{O}_{4}$ & 35.14 & 50.44 & 2.6 & 8.37 & 3.45 & 2.43 & 0.238 & 19.088 & 0.438 \\
\hline $\mathrm{M}-\mathrm{Fe}_{3} \mathrm{O}_{4}$ & 36.1 & 47.07 & 5.46 & 8.85 & 2.52 & 3.51 & 0.245 & 19.554 & 0.453 \\
\hline $\mathrm{Fe}_{3} \mathrm{O}_{4} / \mathrm{GO}$ & 35.75 & 51.51 & 1.88 & 8.57 & 2.29 & 3.74 & 0.240 & 20.818 & 0.412 \\
\hline $\mathrm{M}-\mathrm{Fe}_{3} \mathrm{O}_{4} / \mathrm{GO}$ & 35.95 & 43.56 & 4.66 & 13.52 & 2.21 & 6.12 & 0.310 & 20.869 & 0.648 \\
\hline
\end{tabular}

${ }^{\mathrm{a}}$ Obtained from XPS survey scans with a take-off angle of $45^{\circ}$.

${ }^{b}$ The Osur was the values of $\mathrm{O}$ at the surface of various membranes as determined by XPS spectra with a take-off angle of $45^{\circ}$. The Omat was the values of $\mathrm{O}$ in the matrix of various membranes as determined by elemental analysis (EA). 

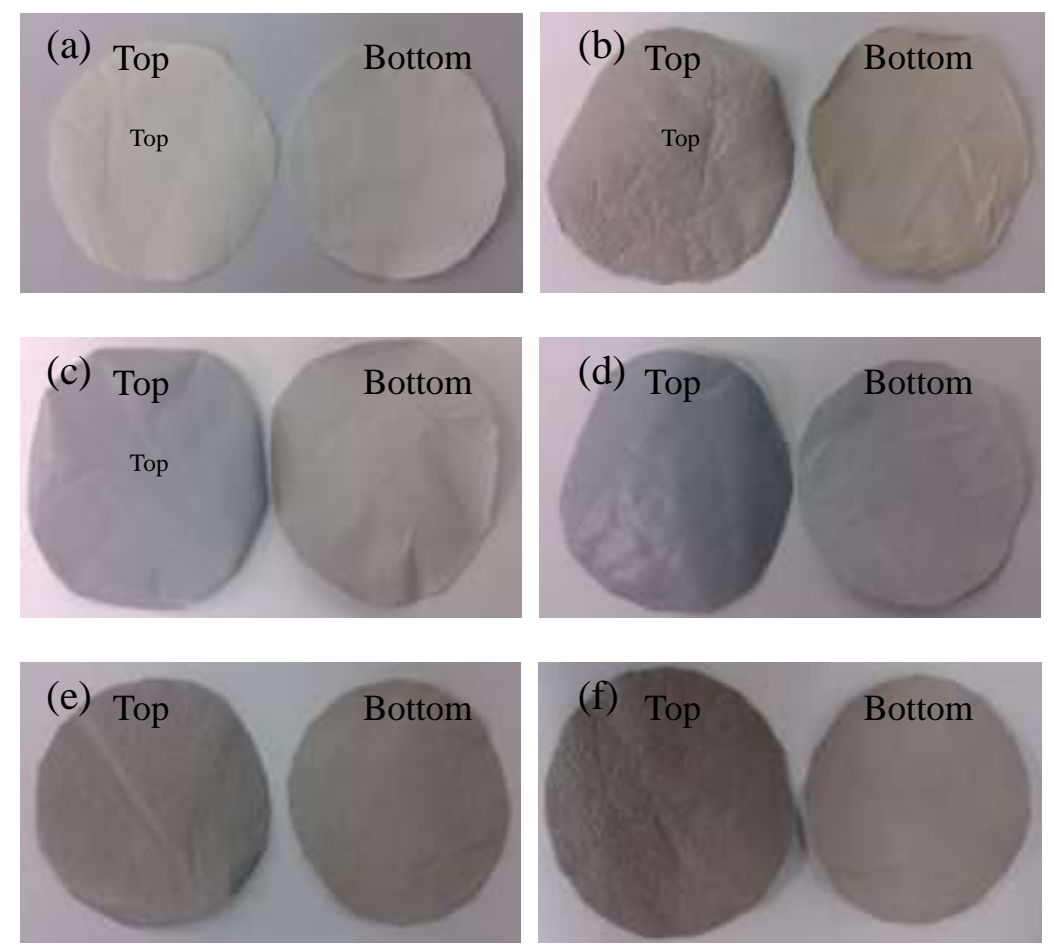

Figure.S9. Digital photographs of top and bottom surface of various membranes: (a) PVDF, (b) GO, (c) $\mathrm{Fe}_{3} \mathrm{O}_{4}$, (d) $\mathrm{M}-\mathrm{Fe}_{3} \mathrm{O}_{4}$, (e) $\mathrm{GO} / \mathrm{Fe}_{3} \mathrm{O}_{4}$ and (f) $\mathrm{M}-\mathrm{GO} / \mathrm{Fe}_{3} \mathrm{O}_{4}$. 


\section{The details for the characters of membranes}
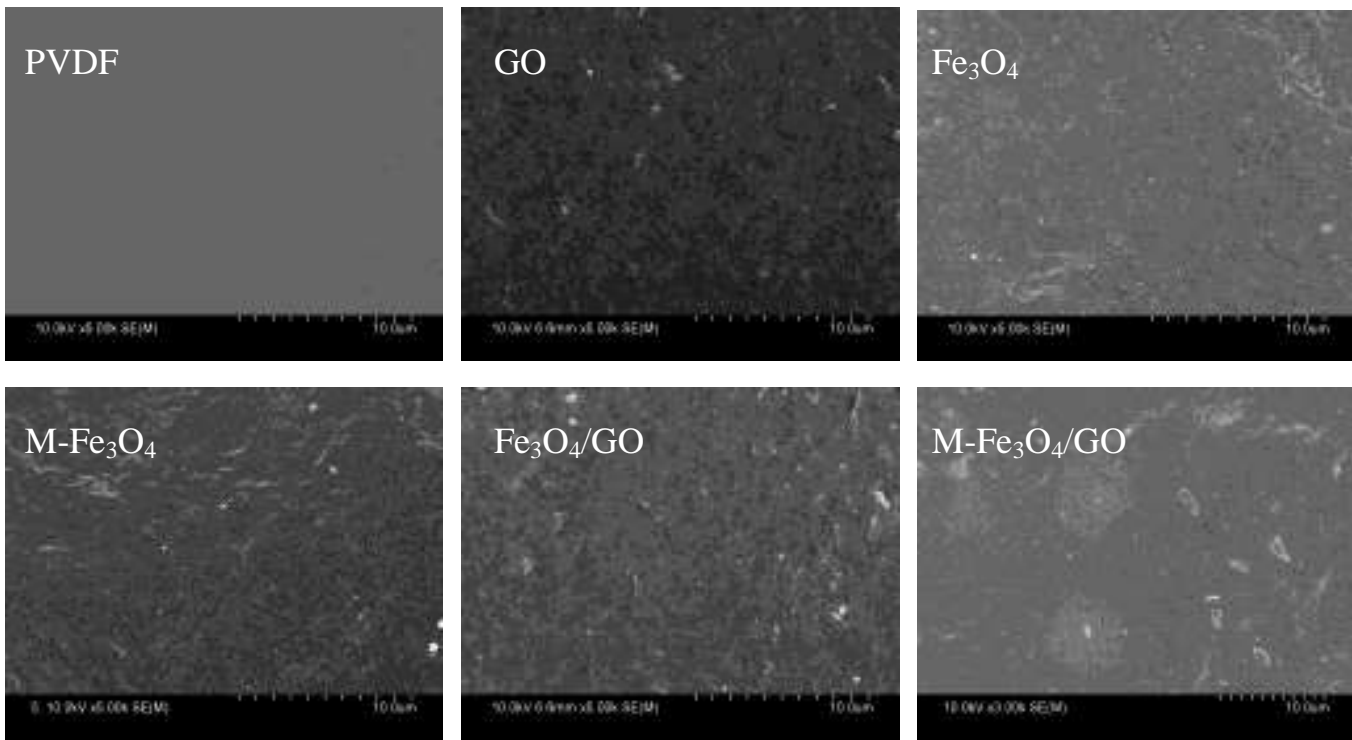

Figure.S10. SEM images of top surface of various membranes.
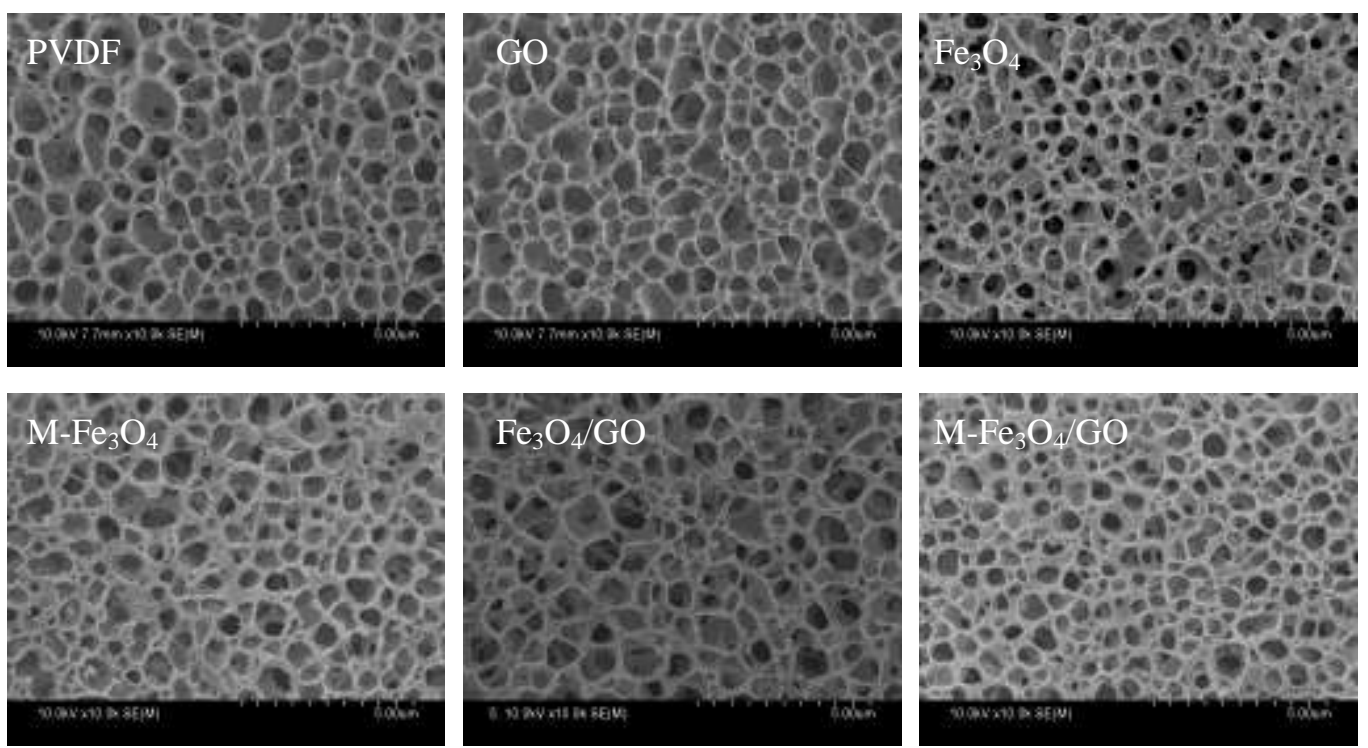

Figure.S11. SEM images of bottom surface of various membranes. 


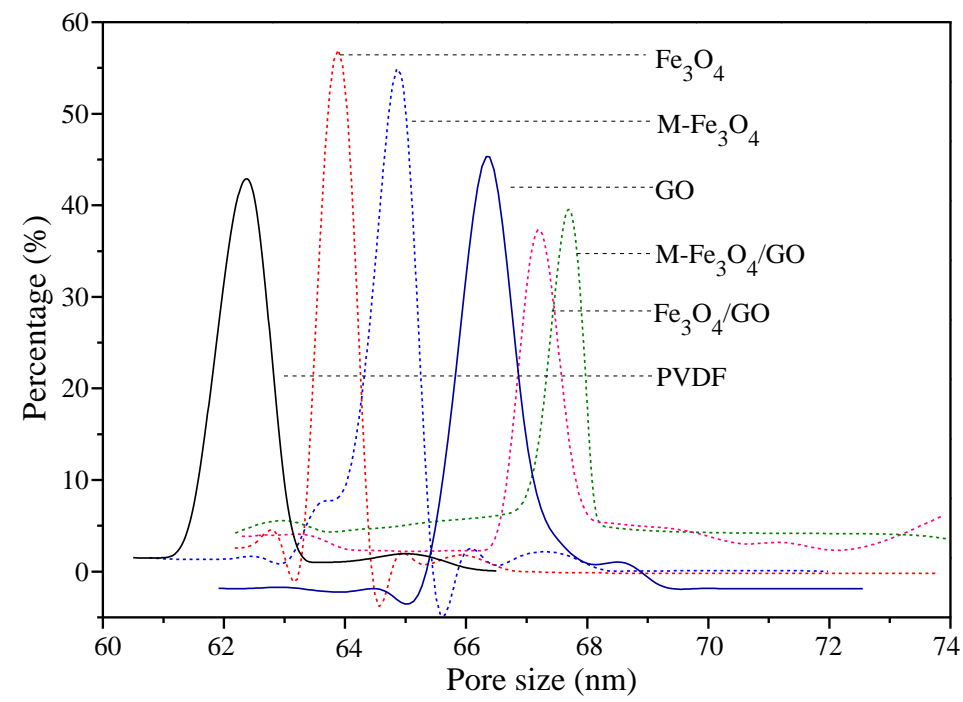

Figure.S12. Pore size distribution of various membranes. 

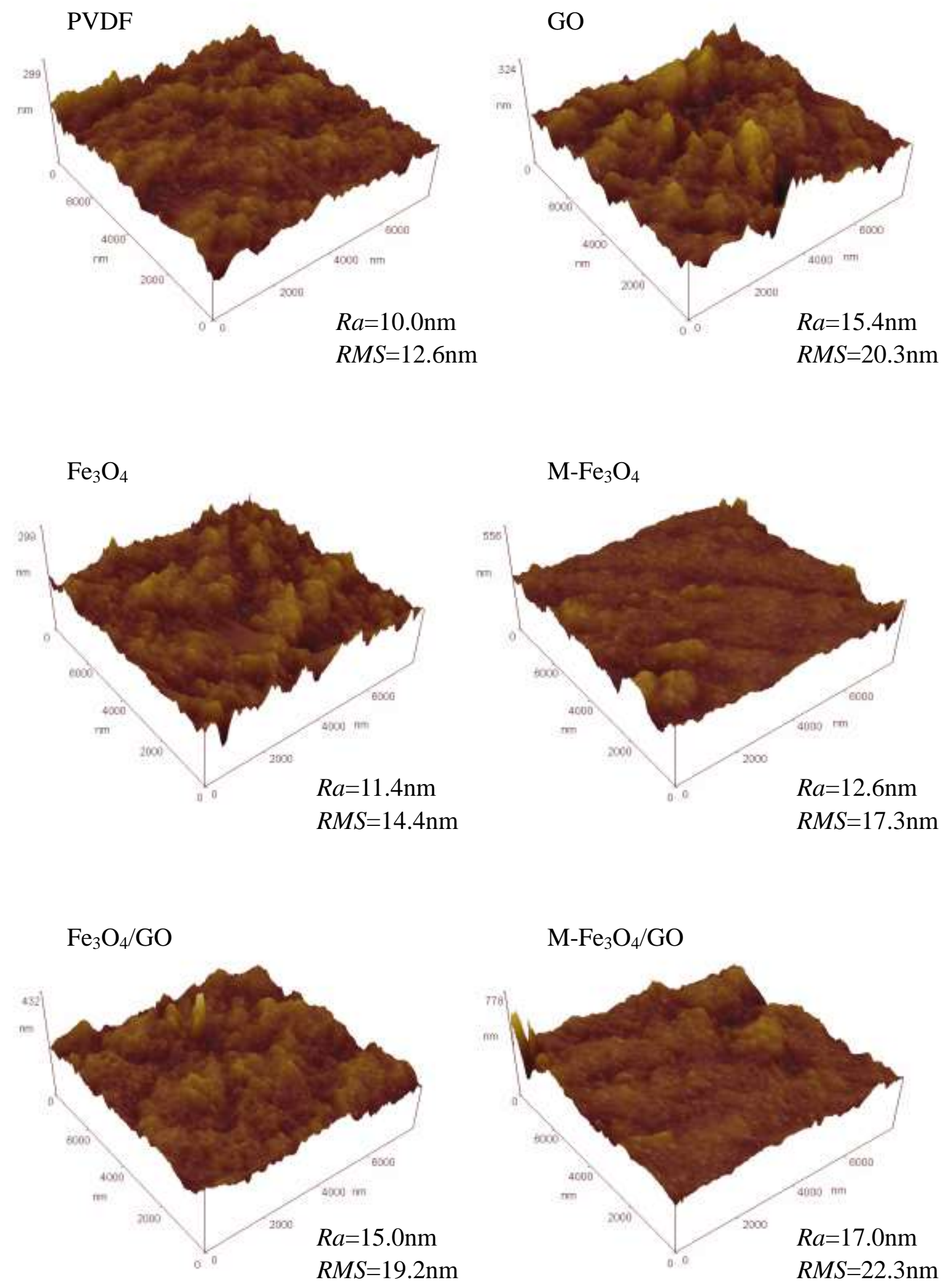

Figure.S13. AFM three-dimensional images of various membranes over a scanning area of $8 \mu \mathrm{m} \times 8 \mu \mathrm{m}$. 


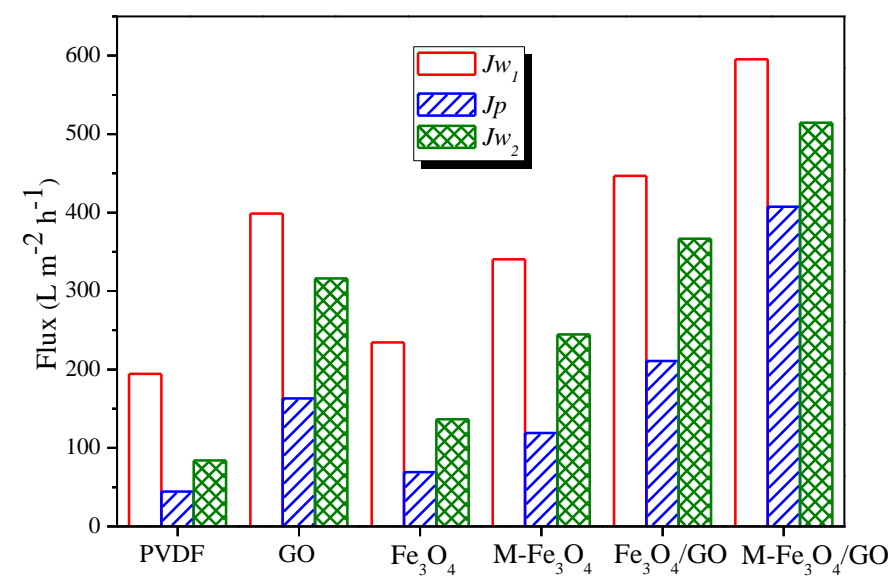

Figure.S14. Pure water flux $\left(J w_{1}\right)$, BSA solution flux $(J p)$ and recovery pure water flux $\left(J w_{2}\right)$ of various membranes.

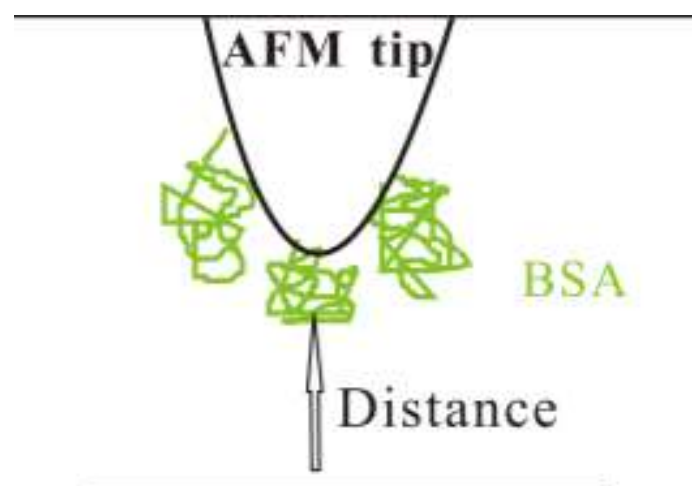

\section{Membrane}

Figure.S15. Schematic for the measurement of force-extension curves between BSA-immobilized tip and membranes. ${ }^{7}$
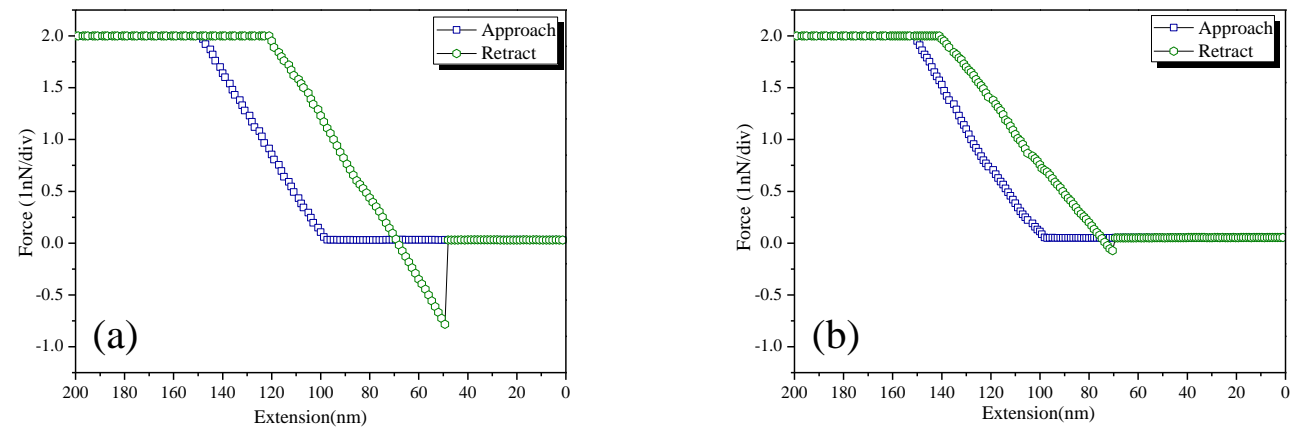

Figure.S16. Force-extension curves of (a) a BSA-immobilized AFM tip against PVDF membrane and (b) an AFM tip without BSA-immobilization against PVDF membrane. Adhesion force experiment of an AFM tip without BSA immobilization 
against PVDF membrane (Figure. S16-b) was done to be compared with that of a BSA-immobilized AFM tip against PVDF membrane (Figure. S16-a). The adhesion force was detected in the same manner when the surface was retracted from the tip and a force-extension curve was then recorded. The adhesion force of an AFM tip without BSA immobilization against PVDF membrane was much smaller than that of a BSA-immobilized AFM tip against PVDF membrane in the magnitude, which illustrated the modification of AFM tip.

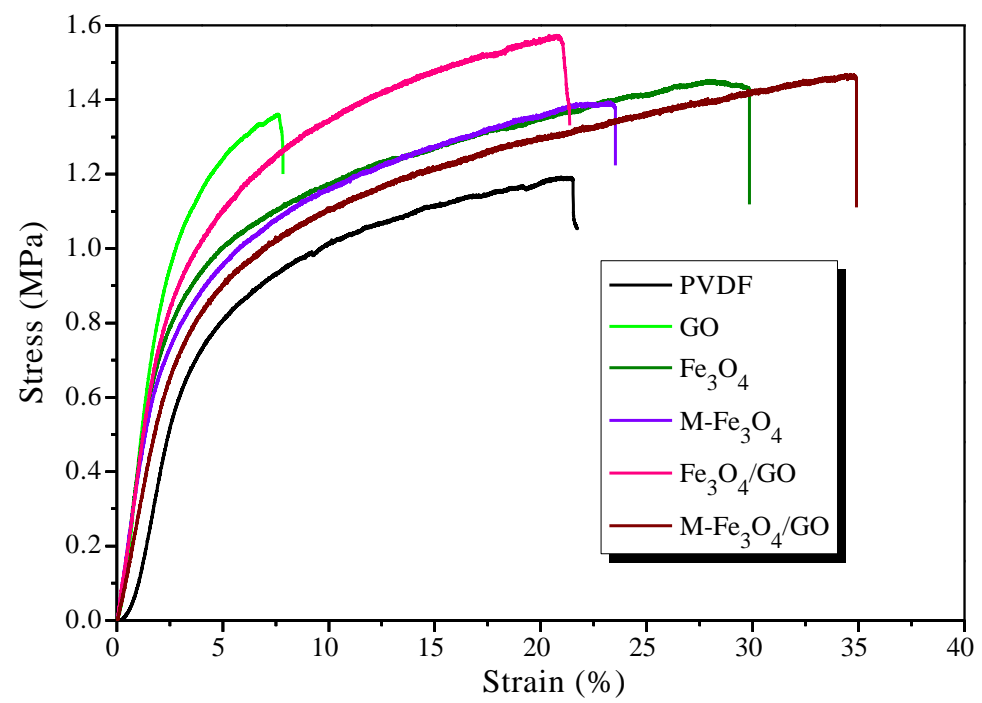

Figure.S17. Stress-strain curves of various membranes. The mechanical strength of hybrid membranes was higher than that of pristine PVDF mmebranes, indicating that supplementation of the membranes with inorganic nanomaterials can boost the mechanical strength of membranes. ${ }^{8-11}$ The mechanical strength of $\mathrm{M}-\mathrm{Fe}_{3} \mathrm{O}_{4} / \mathrm{GO}$ membranes, slightly smaller than that of $\mathrm{Fe}_{3} \mathrm{O}_{4} / \mathrm{GO}$ membranes, was still higher than that of pristine PVDF mmebranes, indicating that manipulating magnetic field induced casting and phase separation highlights new avenues to the development of hybrid membranes with effective reinforced permeation and antifouling performance without sacrificing the mechanical strength. 


\section{References}

1. Li, W.; Xu, Z.; Chen, L.; Shan, M.; Tian, X.; Yang, C.; Lv, H.; Qian, X. A Facile Method to Produce Graphene Oxide-g-poly (L-lactic acid) as An Promising Reinforcement for PLLA Nanocomposites. Chem. Eng. J. 2014, 237, 291-299.

2. Shen, J.; Hu, Y.; Shi, M.; Li, N.; Ma, H.; Ye, M. One Step Synthesis of Graphene Oxide-Magnetic Nanoparticle Composite. J. Phys. Chem. C 2010, 114 (3), 1498-1503.

3. Yang, X.; Zhang, X.; Ma, Y.; Huang, Y.; Wang, Y.; Chen, Y. Superparamagnetic Graphene Oxide- $\mathrm{Fe}_{3} \mathrm{O}_{4}$ Nanoparticles Hybrid for Controlled Targeted Drug Carriers. J. Mater. Chem. 2009, 19 (18), 2710-2714.

4. Yao, Y.; Miao, S.; Liu, S.; Ma, L. P.; Sun, H.; Wang, S. Synthesis, Characterization, and Adsorption Properties of Magnetic $\mathrm{Fe}_{3} \mathrm{O}_{4} @$ Graphene Nanocomposite. Chem. Eng. J. 2012, 184, 326-332.

5. Song, Y.; He, Z.; Hou, H.; Wang, X.; Wang, L. Architecture of $\mathrm{Fe}_{3} \mathrm{O}_{4}$-Graphene Oxide Nanocomposite and Its Application as A Platform for Amino Acid Biosensing. Electrochim.Acta 2012, 71, 58-65.

6 Male, K.; Lam, E; Montes, J; Luong, J. Noninvasive Cell-based Impedance Spectroscopy for Real-time Probing Inhibitory Effects of Graphene Derivatives, ACS Appl. Mater. Interfaces 2012,4, 3643-3649.

7. Xu, Z.; Zhang, J.; Shan, M.; Li, Y.; Li, B.; Niu, J.; Zhou, B.; Qian, X., Organosilane-functionalized Graphene Oxide for Enhanced Antifouling and Mechanical Properties of Polyvinylidene Fluoride Ultrafiltration Membranes. J. Membr. Sci. 2014, 458, 1-13.

8. Huang, Z.Q.; Zheng, F.; Zhang, Z.; Xu, H.T.; Zhou, K.M. The Performance of The PVDF-Fe $\mathrm{O}_{4}$ Ultrafiltration Membrane and The Effect of A Parallel Magnetic Field Used During The Membrane Formation. Desalination 2012, 292, 64-72.

9. Lee, J.; Chae, H.R.; Won, Y. J.; Lee, K.; Lee, C.H.; Lee, H. H.; Kim, I.C.; Lee, J.m. Graphene Oxide Nanoplatelets Composite Membrane with Hydrophilic and Antifouling Properties for Wastewater Treatment. J. Membr. Sci. 2013, 448, 223-230.

10. Yang, L.; Tang, B.; Wu, P. UF Membrane with Highly Improved Flux by Hydrophilic Network Between Graphene Oxide and Brominated Poly (2, 6-dimethyl-1, 4-phenylene oxide). J. Mater. Chem. A 2014, 2 (43), 18562-18573.

11. Yu, L.; Zhang, Y.; Zhang, B.; Liu, J.; Zhang, H.; Song, C. Preparation and Characterization of HPEI-GO/PES Ultrafiltration Membrane with Antifouling and Antibacterial Properties. J. Membr. Sci. 2013, 447, 452-462. 